\title{
Obezite ACSL4 ve GPX4 Aracilı Ferroptozis ile Oksidatif Stresi İndükler
}

\author{
Obesity Induces Oxidative Stress By ACSL4 and GPX4-Mediated Ferroptosis
}

${ }^{1}$ Gülay Sezgin, ${ }^{2}$ Fatih Kar, ${ }^{3}$ Ceyhan Hacıoğlu, ${ }^{4}$ Sema Uslu

'İstanbul Taksim Eğitim ve Araştırma Hastanesi, İstanbul, Türkiye

${ }^{2}$ Kütahya Sağlık Bilimleri Üniversitesi, Fakülte: Mühendislik ve Doğa Bilimleri Fakültesi, Temel Bilimler Bölümü,

Kütahya, Türkiye

${ }^{3}$ Düzce Üniversitesi Tip Fakültesi, Tibbi Biyokimya Anabilim Dal, Düzce, Türkiye

${ }^{4}$ Eskişehir Osmangazi Üniversitesi Tip Fakültesi Tibbi Biyokimya Anabilim Dalı, Eskișehir, Türkiye

\section{Correspondence:}

Fatih KAR

Kütahya Sağlık Bilimleri Üniversitesi, Fakülte: Mühendislik ve Doğa Bilimleri Fakültesi, Kütahya, Türkiye e-mail:fatihkarahasanoglu_@hotmail. com

\begin{abstract}
Özet
Bu çalışmada, vücut kitle indeksine (VKİ) göre oluşturulmuş yetişkin bireylerden oluşan deney gruplarında oksidatif stres belirteçleri ve ferroptoz parametreleri toplam 39 yetişkin birey normal kilolu veya hafif kilolu (VKİ:18.5-29.9), birinci derece obez (VKİ 30-34.9) ve ikinci derecede obez (VKİ:35-39,9) olmak üzere on üçer kisilik üc gruba ayrılmıstır. Kontrol grubundaki sağlıklı bireylerin ve obezite gruplarındaki hastaların serum örneklerinden malondialdehit (MDA), total antioksidan kapasite (TAS), total oksidan kapasite (TOS), glutatyon (GSH), asil-CoA sentetaz uzun zincirli aile üyesi 4 (ACSL4) ve glutatyon peroksidaz 4 (GPx4) seviyeleri ölçülmüştür. TOS seviyeleri, kontrol grubu ile karșlaștırıldığında 1 . derece obez ve 2 . derece obez hastalarda artarken $(\mathrm{p}<0.0001)$ TAS seviyeleri, 1 . derece obez ve 2 . derece obez hastalarda azalmıștır $(\mathrm{p}<0.001)$. MDA seviyeleri, kontrol grubuna kıyasla 1. derece obez $(\mathrm{p}<0,001)$ ve 2 . derece obez hastalarda $(\mathrm{p}<0,0001)$ artmıştır. GSH seviyeleri ise obezite derecesi arttıkça düşüş göstermiştir $(\mathrm{p}<0.001)$. Kontrol grubuna kıyasla 1 . derece obez ve 2 . derece obez hastaların ACSL4 seviyeleri artış gösterirken $(\mathrm{p}<0.001)$, GPx4 seviyeleri her iki obez gupta da azalmıştır $(\mathrm{p}<0.001)$. Obezite derecesi arttıkça lipit peroksidasyonu ve oksidatif stres artmaktadır. Ek olarak kontrol grubuna kıyasla obez bireylerde GPx4 seviyelerinin azalışı ve ACSL4 seviyelerinin artışı birlikte değerlendirildiğinde obezitenin ferroptozu indüklediği düşünülebilir.
\end{abstract}

Anahtar Kelimeler: ACSL4; ferroptoz; GPx4; obezite; oksidatif stres; lipit peroksidasyonu

\section{Abstract}

In this study, the parameters of oxidative stress markers and ferroptosis were evaluated in experimental groups of adult individuals, which were formed according to the body mass index (BMI). A total of 39 adult patients were normal weight or overweight (BMI: 18.5-29.9), first degree obese (BMI 30-34.9) and second degree obese (BMI: 35-39.9) were divided into three groups of thirteen each.. From the serum samples of healthy individuals in the control group and patients in the obesity groups, malondialdehyde (MDA), total antioxidant capacity (TAS), total oxidant capacity (TOS), glutathione (GSH), Acyl-CoA synthetase long chain family member 4 (ACSL4) and glutathione peroxidase $4(\mathrm{GPx} 4)$ levels were measured. Compared to the control group, TOS levels increased in grade 1 and grade 2 obese patients $(p<0.0001)$, while TAS levels decreased in grade 1 obese and grade 2 obese patients $(p<0.001)$. MDA levels were increased in grade 1 obese $(p<0.001)$ and grade 2 obese patients $(p<0.0001)$ compared to the control group. GSH levels decreased as the degree of obesity increased $(\mathrm{p}<0.001)$. Compared to the control group, ACSL4 levels of 1 st and 2 nd obese patients increased $(\mathrm{p}<0.001)$, while GPx4 levels decreased in both obese groups $(\mathrm{p}<0.001)$. As the degree of obesity increases, lipid peroxidation and oxidative stress increase. In addition, when the decrease in GPx4 levels and the increase in ACSL4 levels in obese individuals compared to the control group are evaluated together, it can be thought that obesity induces ferroptosis.

Keywords:ACSL4; ferroptosis; GPx4; obesity; oxidative stress; lipid peroxidation 


\section{Giriş}

Obezite sağlığı bozabilecek ve mortaliteyi artırabilecek aşırı yağ birikimi ile karakterize multifaktöriyel kökenli kronik bir hastalıktır (1). Artan kanitlar, oksidatif stresin obezite ile ilişkili komplikasyonların meydana gelmesinde kritik faktör olarak rol oynadığını göstermektedir. Obezite başlı başına NADPH oksidazlardan süperoksit oluşumu, oksidatif fosforilasyon, gliseraldehit oto-oksidasyonu, protein kinaz $\mathrm{C}$ aktivasyonu, poliol ve heksozamin yolakları gibi çeşitli biyokimyasal mekanizmalar yoluyla sistemik oksidatif stresi indükleyebilir (2). Obezitede oksidatif strese katkıda bulunan diğer faktörler hiperglisemi, yüksek lipit seviyeleri, vitamin ve mineral eksiklikleri, kronik inflamasyon, hiperleptinemi, aşırı vücut ağırlığını taşımak için artan kas aktivitesi, bozulmuş mitokondriyal fonksiyon ve diyet türüdür (1, 3-10). Oksidatif stres obezitenin bir sonucu olabileceği gibi aynı zamanda obezitenin bir tetikleyicisi de olabilir. Oksidatif stres, beyaz yağ dokusu birikimini uyararak ve gida alımını değiştirerek obezitenin gelişiminde nedensel bir rol oynayabilir. Hücre kültürü ve hayvan çalışmaları, oksidatif stresin adiposit öncesi proliferasyonunu, adiposit farklılaşmasını ve olgun adipositlerin boyutunu arttırdığını göstermektedir (11-13). Reaktif oksijen türleri (ROS), tokluk ve açlık davranışını kontrol eden hipotalamik nöronlar üzerinde farklı etkiler uygulayarak vücut ağırlığının denetimine etki edebilir (14). MDA, iyi bilinen bir oksidatif stres biyobelirtecidir. VKI ve MDA arasında önemli bir pozitif korelasyon gözlenmiştir (15). $\mathrm{Cu}-\mathrm{Zn}$ süperoksit dismutaz (SOD), katalaz (CAT) ve glutatyon peroksidaz (GPx) gibi antioksidan enzimlerin aktiviteleri, obez deneklerin eritrositlerinde obez olmayan kontrollere göre daha düşük bulunmuştur $(11,16)$.

Ferroptozis, son y1llarda keşfedilen genellikle büyük miktarda demir birikimi ve lipit peroksidasyonun eşlik ettiği GPx4 tarafindan kontrol edilen, düzenlenmiş nekrotik hücre ölümünün bir ş̧eklidir $(17,18)$. ACSL4, ferroptoz duyarlılığını belirleyen çoklu doymamış yă asitleri (PUFA'lar) metabolizması için önemli bir izozimdir (19). ACSL4, ferroptozun hassas bir biyobelirteci olmasının yanında ferroptoza önemli bir katkı sağlar (20). Bu çalışmanın amacı obezite derecesine bağlı olarak oksidatif stres ve ferroptoz biyobelirteçlerinin nasıl değiştiğini saptamak, obezite ile oksidatif stres ve ferroptoz arasındaki ilişkiyi araştırmaktır.

\section{Gereç ve Yöntemler}

\section{Araştırma Yeri, Zamanı ve Örneklem Seçimi}

Çalışmaya 01.10.2017- 30.04.2018 tarihleri arasında özel bir Fizik Tedavi ve Rehabilitasyon Merkezi'ne obezite tedavisi amaciyla başvuran 25-65 yaş arasındaki 39 kadın dahil edilmiştir. Çalışmaya başlamadan önce katılımcılardan yazılı onay alınmıştır. Aktif olarak kanser tedavisi görenler veya kanser öyküsüne sahip bireyler, herhangi bir böbrek hastalığı, diyabet( Tip I, Tip II) veya ağır kardiyovasküler hastalığı olan bireyler çalışmaya dahil edilmemiştir. Çalışmaya dahil edilen bireyler VKI' lerine göre üç gruba ayrılmıştır. Kontrol grubu normal $(18,5 \leq \mathrm{VKI}$ $\left.24,99 \mathrm{~kg} / \mathrm{m}^{2}\right)$ ve hafif kilolu $(25 \leq \mathrm{VK} \mathbf{I} \leq 29.99$ $\left.\mathrm{kg} / \mathrm{m}^{2}\right)$ on üç sağlıklı bireyden, ikinci grup (30 $\leq$ BKI $\leq 34,99 \mathrm{~kg} / \mathrm{m}^{2}$ ) ve üçüncü grup ise $\left(35 \leq\right.$ BKI $\left.\leq 39,99 \mathrm{~kg} / \mathrm{m}^{2}\right)$ obez on üçer bireyden oluşmaktadır. Bu çalışma Eskişehir Osmangazi Üniversitesi Klinik Araştırma Komitesi tarafindan 10.08.2017 tarih ve 80558721/212 sayılı kararı ile onaylanmıştır.

\section{Materyal Metot}

Kontrol grubundaki sağlıklı bireylerin ve obezite gruplarındaki hastaların serum örneklerindeki TOS, MDA, TAS, GSH, ACSL4 ve GPx4 seviyeleri ticari olarak mevcut kitler (sirasiyla RelAssay Total OxidantStatus (TOS), MBS263626, RelAssay Total AntioxidantStatus (TAS), MBS042904, MBS9331516, CSB-EL009869HU) kullanılarak üretici firma talimatları doğrultusunda mikroplaka okuyucu yardımıyla ölçülmüştür.

\section{Istatistiksel analiz}

İstatistiksel analiz sırasında GraphPad Prism 7 programı kullanılmıştır. Deneysel veriler ortalama \pm standart sapma olarak sunulmuştur. Sonuçların normallik analizi 
Kolmogorow-Smirnov normallik testi yardımıyla yapılmıştır. Normal olarak dağıtılan veriler, tek yönlü varyans analizi (ANOVA) kullanılarak değerlendirilmiş ve çoklu karşılaştırmalarda Tukey post-hoc testi ile analiz edilmiştir. $p<0.05$ istatistiksel olarak anlamlı kabul edilmiştir.

\section{Bulgular}

\section{Obezitenin oksidatif stres biyobelirteçleri üzerindeki etkileri}

Obez hastalarda obezitenin derecesine bağlı TOS seviyelerinde artış olduğu tespit edilmiştir (Şekil 1A). Serum TOS seviyeleri, prooksidan/oksidan dengesinin ve vücuttaki oksidatif yükün bir göstergesidir. TOS seviyeleri, kontrol grubu ile karşılaștırıldı ğında 1. derece obez hastalarda $\% 66.6$ ve 2 . derece obez hastalarda $\% 108.3$ oranında artmıștır $(\mathrm{p}<0.0001)$.

Lipit peroksidasyonunun biyokimyasal analizi için sağllk ve obez bireylerde MDA seviyeleri ölçülmüştür (Şekil 1B). Sağlıklı kişilerle kıyaslandığında obez hastaların MDA seviyelerinde artış kaydedilmiștir. MDA seviyeleri, kontrol grubuna kiyasla 1. derece obez hastalarda \%28.5 $(p<0.001)$ ve 2 . derece obez hastalarda \%142.8 $(\mathrm{p}<0.0001)$ oranında artmıştır.
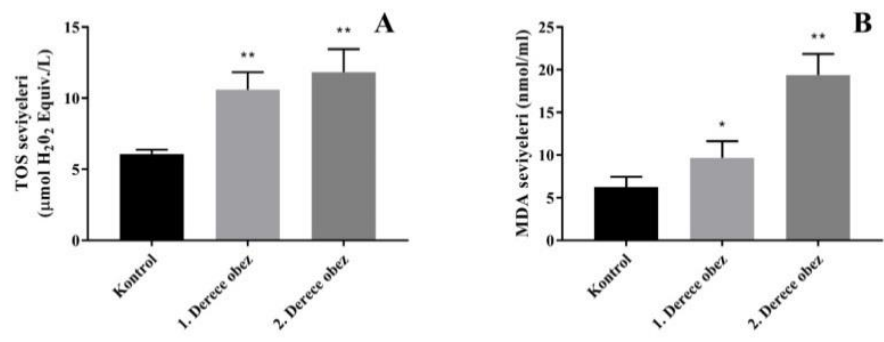

Şekil 1. Obezite derecesine bağll oksidatif stres parametreleri. A: TOS seviyeleri; B: MDA seviyeleri. * $p<0.001$ ve $* * p<0.0001$ kontrol grubu ile karşılaştırıldı̆̆ında

Obezitenin antioksidan seviyeleri üzerindeki etkileri

Şekil 2A'da görüldüğü gibi, TAS seviyelerinde obezite derecesine bağlı olarak istatiksel olarak anlamlı bir azalış olduğu saptanmıştır. TAS seviyeleri, kontrol grubuna k1yasla 1 . derece obez hastalarda $\% 29.4$ ve 2. derece obez hastalarda $\% 40.2$ oranında azalmıştır $(\mathrm{p}<0.001)$.
GSH seviyeleri, obezite derecesindeki artış ile birlikte azalış göstermiştir (Şekil 2B). Obez hastalardaki GSH seviyeleri, kontrol grubundan önemli bir farkl1l1k göstermiştir $(\mathrm{p}<0.0001)$. Kontrol grubu ile karşılaştırıldığında, $1 . \quad$ derece obez hastalardaki ve 2 . derece obez hastalardaki GSH seviyeleri sirasiyla $\% 60.8$ ve $\% 294.5$ oranında düşüş göstermiştir. 

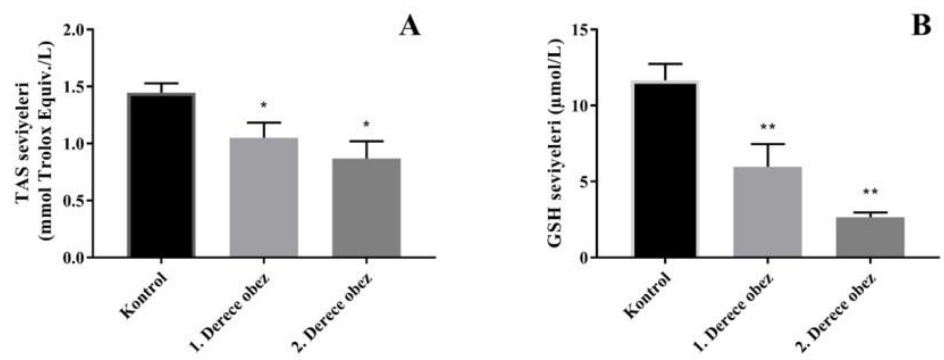

Şekil 2. Obezite derecesine bağll antioksidan parametrelerin seviyeleri. A: TAS seviyeleri; B: GSH seviyeleri. ${ }^{*} p$ $<0.001$ ve ** $p<0.0001$ kontrol grubu ile karşılaştırıldiğında

\section{Obezitenin ferroptoz biyobelirteçleri seviyelerinde sırasıla \%22.5 ve \%39.1'lik üzerindeki etkileri artış göstermiştir.}

ACSL4 seviyeleri, obezite derecesine bağl1 olarak ile artı̧̧ göstermiştir (Şekil 3A). Obez hasta gruplarındaki ACSL4 seviyeleri, kontrol grubundan önemli bir farkl1lık göstermiştir $(\mathrm{p}<0,001)$. Kontrol grubu ile karşılaştırıldığında, 1. derece obez ve 2 . derece obez gruplarındaki ACSL4

Şekil 3B'de görüldüğü gibi, ferroptozun önemli parametrelerinden biri olan GPx4 seviyeleri, obezite derecesine bağımlı bir azalış göstermiştir. GPx4 seviyeleri, kontrol grubuna kiyasla 1. derece obez hastalarda $\% 30.7$ ve 2 . derece obez hastalarda $\% 55.2$ oranında azalmıştır $(\mathrm{p}<0.001)$.
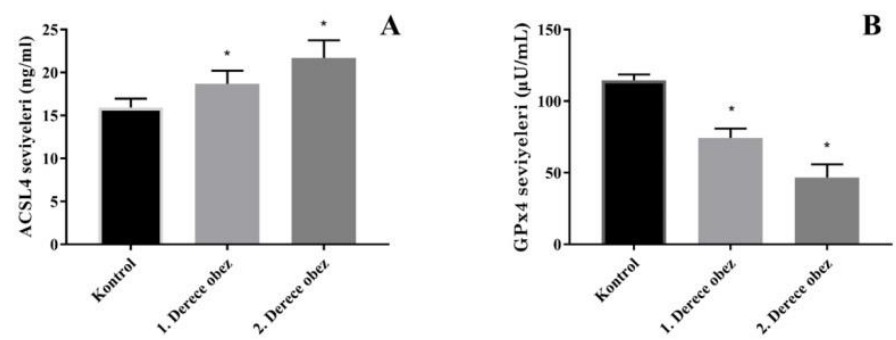

Şekil 3. Obezite derecesine bağll ferroptoz seviyeleri. A: ACSL seviyeleri; B: GPx4 seviyeleri. * $p<0.001$ kontrol grubu ile karşılaştırıldı̆̆ı̀nda

\section{Tartışma ve Sonuç}

Oksidatif stres, hücresel düzeyde oksidanlar ve antioksidanlar arasındaki dengesizliği ifade eder (21). Birçok çalışma, obez kişilerin obez olmayan kişilere göre daha yüksek oksidatif stres düzeylerine sahip olduğunu göstermiştir $(11,22,23)$. MDA, çoklu doymamış yağ asitlerinin oksidatif bozunmasında son ürün olarak üretilen lipit peroksidasyonunun önemli bir göstergesi olarak kabul edilmiştir (24). Obez olmayan sağliklı kontrollere k1yasla obez deneklerde oksidatif stresin bir belirteci olarak MDA düzeylerinde önemli bir artış ve ayrıca obezitenin kendi başına plazma lipit peroksidasyonu için bağımsız bir risk faktörü olduğu öne sürülmüştür $(25,26)$. Çalışmamızda obezite derecesi arttıkça MDA düzeylerinin arttığ 1 saptanmıştır. Aynı zamanda obezitenin derecesine bağlı olarak TOS seviyeleri artarken, TAS seviyeleri azalmıştır. Sonuçlarımıza paralel olarak alkole 
bağlı olmayan karaciğer hastalığı olan obez çocukların kontrol grubuna güre TOS düzeylerinin daha yüksek TAS düzeylerinin ise daha düşük olduğu bildirilmiştir (27). Obez ve metabolik sendromlu çocukların total oksidan ve antioksidan durumları üzerine yapılan bir başka çalışmada ise VKİ artışı ile TAS, TOS düzeylerinin yükseldiği gösterilmiştir (28). Erişkin bireylerde VKİ' nin oksidatif stres belirteçlerine etkisini araştıran bir başka çalışma TOS seviyelerinin VKI arttıkça yükseldiğini ancak TAS seviyelerinde anlamlı bir değişim olmadığını sağtamıştır (29).

GSH, protein olmayan tiyol gruplarının yaklaşık \%90'inı temsil eder, oksidatif ve serbest radikal aracılı hasara karşı koruyucu bir role sahiptir. GSH düzeylerindeki genel bir düşüş, obezite dahil kronik inflamatuar hastalıklarla ilişkilendirilmiştir. Glutatyon metabolizması karmaşık olmakla birlikte obezite ile ilgili yanıtları düzenlemede işlev gören çeşitli enzimler için bir kofaktördür. Örneğin, GSH' nin azalması enerji metabolizmasını arttırır ve yağ birikimini azaltırken, GPx aktivitesinin artması insülin direncini indükler (30-32). VKİ ve glutatyon arasındaki ilişkiyi araştıran bir çalışma normal, hafif kilolu ve obez bireyler arasinda GSH seviyelerinde istatistiksel olarak anlamlı fark bulamamıştır. Ancak bireyler VKI' ye göre değil vücut yă̆ oranına göre normal, hafif kilolu ve obez olarak sinıflandırıldığında üç grup arasında istatistiksel olarak anlamlı fark saptanmış $(p<0,05)$ ve obez bireylerin en düşük GSH seviyelerine sahip olduğu bulunmuştur (33). Hem obez hem de normal kiloda olmasına rağmen vücut yağ yüzdesi $\% 30$ ' dan fazla olan kadınlarda normal kiloda olan kadınlara göre daha düşük GSH seviyeleri gösterilmiştir (34). Benzer şekilde çalışmamızda obezite derecesindeki artış ile birlikte GSH seviyeleri, azalış göstermiştir. Buna karşın obezitesi olan çocuklarda daha yüksek eritrosit GPx aktivitesi ve GSH seviyeleri bildirilmiştir. $\mathrm{Bu}$ durum obezite nedeniyle artan oksidatif yüke yanıt olarak telafi edici bir mekanizma olarak açıklanabilir (35).

Lipit hidroperoksitler, lipit peroksidasyonu sürecinde anahtar ara ürünlerdir. Lipit hidroperoksidaz glutatyon peroksidaz 4 (GPX4), lipit hidroperoksitleri lipit alkollere dönüştürür ve bu işlem, toksik lipit ROS' larının demire $(\mathrm{Fe} 2+)$ bağımlı oluşumunu engeller (36). Yağ metabolizması disfonksiyonu ve obezite komorbiditelerinde enzimatik ve enzimatik olmayan lipit peroksidasyonunun potansiyel rolü olmasına rağmen obezitede GPx4 aktivitesinin etkisi hakkında halen çok az şey bilinmektedir (37). Gpx4' ün iki polimiorfizmi obezite ile ilişkilendirilmiştir (38). Çalışmamızda GPX4 polimorfizmlerine bakılmamış olmasına rağmen kontrol grubuna kiyasla obez gruplarda GPx4 seviyeleri azalmıştır $(\mathrm{p}<0.001)$. GPx4 fonksiyonunun inhibisyonu, lipit peroksidasyonuna yol açar ve demire bağımlı, apoptotik olmayan bir hücre ölümü formu olan ferroptozun indüklenmesine neden olabilir (39). Çalışmamızda ek olarak obez hasta gruplarındaki ACSL4 seviyelerinin kontrol grubundan önemli derecede yüksek olduğunu bulduk $(\mathrm{p}<0,001)$. Son çalışmalar, spesifik olarak ACSL4 tarafindan fosfolipite katılan araşidonik asit lipit peroksidasyonunun, ferroptoza aracilik ettiğini göstermiştir. (18,40-41). Ratlarda yapılan in vivo bir çalışma yüksek yağ ile beslenme sonucu ratlarm adipositlerinde ACSL4 ekspresyonunun önemli ölçüde arttığını saptamıştır (42). Bu çalışmada da benzer şekilde ACSL4 seviyeleri, obezite derecesine bağlı olarak artış göstermiştir $(\mathrm{p}<0,001)$.

Sonuç olarak obezite derecesi arttıkça MDA ve TOS seviyelerinin artması ve TAS, GSH, seviyelerinin azalmasi lipit peroksidasyonunun ve oksidatif stresin obezlerde daha yüksek olduğunu göstermektedir. Son yıllarda ACSL4 ve GPx4' ün ferroptoz mekanizmasındaki rolleri araştırılmasına rağmen obezite ile ilişkisini araştıran çalışmalar sınırlıdır. Sağlıklı bireylere k1yasla obez bireylerde GPx4 seviyelerinin azalış1 ve ACSL4 seviyelerinin artışı birlikte değerlendirildiğinde obezitenin ferroptozu indüklediği düşünülebilir. Ancak obezite ve ferroptoz ilişkisinin aydınlatılması için ileri çalışmalara ihtiyaç vardır. 


\section{KAYNAKLAR}

1. Fernández-Sánchez A, Madrigal-Santillán E, Bautista M, Esquivel-Soto J, Morales-González Á, Esquivel-Chirino $\mathrm{C}$ et al. Inflammation, oxidative stress, and obesity. International journal of molecular sciences, 2011;12:3117-32.

2. Manna P, Jain SK. Obesity, oxidative stress, adipose tissue dysfunction, and the associated health risks: causes and therapeutic strategies. Metabolic syndrome and related disorders, 2015;13:423-44.

3. Aronson D, Rayfield EJ. How hyperglycemia promotes atherosclerosis: molecular mechanisms. Cardiovascular diabetology, 2002;1:1-10.

4. Bełtowski J, Wójcicka G, Górny D, Marciniak A. The effect of dietary-induced obesity on lipid peroxidation, antioxidant enzymes and total plasma antioxidant capacity. $J$ Physiol Pharmacol. 2000;51:883-96

5. Ortega RM, Rodríguez-Rodríguez E, Aparicio A, Jiménez-Ortega AI, Palermos C, Perea JM, et al. Young children with excess of weight show an impaired selenium status. International journal for vitamin and nutrition research, 2012;82:121.

6. Strauss RS. Comparison of serum concentrations of $\alpha$-tocopherol and $\beta$-carotene in a cross-sectional sample of obese and nonobese children (NHANES III). The Journal of pediatrics, 1999;134:160-65.

7. Bouloumié A, Marumo T, Lafontan M, Busse R. Leptin induces oxidative stress in human endothelial cells. The FASEB Journal, 1999;13:1231-38.

8. Salvadori A, Fanari P, Fontana M, Buontempi L, Saezza A, Baudo S, et al. Oxygen uptake and cardiac performance in obese and normal subjects during exercise. Respiration, 1999;66: 25-33.

9. Martinez JA. Mitochondrial oxidative stress and inflammation: an slalom to obesity and insulin resistance. Journal of physiology and biochemistry, 2006;62:303-6.

10. Khan NI, Naz L, Yasmeen G. Obesity: an independent risk factor for systemic oxidative stress. Pakistan journal of pharmaceutical sciences, 2006;19:62-65.

11. Furukawa S, Fujita T, Shimabukuro M, Iwaki M, Yamada Y, Nakajima Y, et al. Increased oxidative stress in obesity and its impact on metabolic syndrome. The Journal of clinical investigation, 2004;114:1752-61.

12. Lee H, Lee, Y. J., Choi, H., Ko, E. H., \& Kim, J. W.. Reactive oxygen species facilitate adipocyte differentiation by accelerating mitotic clonal expansion. Journal of Biological Chemistry, 2009;284,;10601-609.

13. Higuchi, M., Dusting, G. J., Peshavariya, H., Jiang, F., Hsiao, S. T. F., Chan, E. C., \& Liu, G. S. Differentiation of human adipose-derived stem cells into fat involves reactive oxygen species and Forkhead box $\mathrm{O} 1$ mediated upregulation of antioxidant enzymes. Stem cells and development, 2013;226;878-88.

14. Horvath, T. L., Andrews, Z. B., \& Diano, S. (2009). Fuel utilization by hypothalamic neurons: roles for ROS. Trends in Endocrinology \& Metabolism, 20(2), 78-87.

15. Vincent, H. K., \& Taylor, A. G. Biomarkers and potential mechanisms of obesity-induced oxidant stress in humans. International journal of obesity, 2006;303:400-18

16. Olusi, S. O. Obesity is an independent risk factor for plasma lipid peroxidation and depletion of erythrocyte cytoprotectic enzymes in humans. International journal of obesity, 2002;269:115964.

17. Li, J., Cao, F., Yin, H. L., Huang, Z. J., Lin, Z. T., Mao, N., ... \& Wang, G. Ferroptosis: past, present and future. Cell death \& disease, 2020; 112: 1-13.

18. Doll, S., Proneth, B., Tyurina, Y. Y., Panzilius, E., Kobayashi, S., Ingold, I., ... \& Conrad, M. (2017). ACSL4 dictates ferroptosis sensitivity by shaping cellular lipid composition. Nature chemical biology, 13(1), 91-98.

19. Cui, Y., Zhang, Y., Zhao, X., Shao, L., Liu, G., Sun, C., ... \& Zhang, Z. ACSL4 exacerbates ischemic stroke by promoting ferroptosis-induced brain injury and neuroinflammation. Brain, Behavior, and Immunity, 2021; 93:312-21.

20. Yuan, H., Li, X., Zhang, X., Kang, R., \& Tang, D. Identification of ACSL4 as a biomarker and contributor of ferroptosis. Biochemical and biophysical research communications, 2016; 478: 1338-43.

21. Sies, H. Biochemistry of oxidative stress. Angewandte Chemie International Edition in English, 1986;25: 1058-71.

22. Keaney Jr, J. F., Larson, M. G., Vasan, R. S., Wilson, P. W., Lipinska, I., Corey, D., ... \& Benjamin, E. J. Obesity and systemic oxidative stress: clinical correlates of oxidative stress in the Framingham Study. Arteriosclerosis, thrombosis, and vascular biology, 2003; 23: 434-39.

23. Olusi, S. O. Obesity is an independent risk factor for plasma lipid peroxidation and depletion of erythrocyte cytoprotectic enzymes in humans. International journal of obesity, 2002:26: 115964.

24. Horton, A. A., Fairhurst, S., \& Bus, J. S. (). Lipid peroxidation and mechanisms of toxicity. CRC Critical Reviews in Toxicology, 1987;18, 27-79.

25. Bhale, DV, Patil, DS ve Mahat, RK Obez erkek bireylerde oksidatif stresin bir belirteci olarak malondialdehitin (MDA) incelenmesi. Int $J$ Son Trendler Sci Technol , 2014;10 : 51-2

26. Sankhla, M., Sharma, T. K., Mathur, K., Rathor, J. S., Butolia, V., Gadhok, A. K., ... \& Kaushik, G. G. Relationship of oxidative stress with obesity and its role in obesity induced metabolic syndrome. Clinical laboratory, 2012; 58: 385-92.

27. Pirgon, Ö., Bilgin, H., Çekmez, F., Kurku, H., \& Dündar, B. N. Association between insulin resistance and oxidative stress parameters in obese adolescents with non-alcoholic fatty liver disease. Journal of clinical research in pediatric endocrinology, 2013;5: 33. 
28. Eren, E., Abuhandan, M., Solmaz, A., \& Taşkın, A. Serum paraoxonase/arylesterase activity and oxidative stress status in children with metabolic syndrome. Journal of clinical research in pediatric endocrinology, 2014;6, 163.

29. Söğüt, İ., Aydın, A. Ş., Gökmen, E. S., Atak, P. G., Erel, Ö., \& DeGrigo, U. G. Evaluation of Oxidative Stress and Thiol-Disulfide Parameters According to the Body Mass Index in Adult Individuals. Erciyes Medical Journal/Erciyes Tip Dergisi, 2018;40.

30. Galinier, A., Carrière, A., Fernandez, Y., Carpéné, C., André, M., Caspar-Bauguil, S., ... \& Casteilla, L. Adipose tissue proadipogenic redox changes in obesity. Journal of Biological Chemistry, 2006; 281: 12682-687.

31. Faber, P., Johnstone, A. M., Gibney, E. R., Elia, M., Stubbs, R. J., Duthie, G. G., ... \& Lobley, G. E. The effect of rate of weight loss on erythrocyte glutathione concentration and synthesis in healthy obese men. Clinical Science, 2002;102: 569-77.

32. Picklo, M. J., Long, E. K., \& Vomhof-DeKrey, E. E. Glutathionyl systems and metabolic dysfunction in obesity. Nutrition reviews, 2015; 73: 858-68.

33. Brown, L. A., Kerr, C. J., Whiting, P., Finer, N., McEneny, J., \& Ashton, T. (). Oxidant stress in healthy normal-weight, overweight, and obese individuals. Obesity, 2009;17: 460-66.

34. Di Renzo, L., Galvano, F., Orlandi, C., Bianchi, A., Di Giacomo, C., La Fauci, L., ... \&De Lorenzo, A. (). Oxidative stress in normal-weight obese syndrome. Obesity, 2010;18: 2125-30.

35. Alkazemi, D., Rahman, A., \& Habra, B. Alterations in glutathione redox homeostasis among adolescents with obesity and anemia. Scientific Reports, 2021;11: 1-12.

36. Forcina, G. C., \& Dixon, S. J. . GPX4 at the crossroads of lipid homeostasis and ferroptosis. Proteomics, 2019;19: 1800311.

37. Kobayashi, H., Matsuda, M., Fukuhara, A., Komuro, R., \& Shimomura, I. Dysregulated glutathione metabolism links to impaired insulin action in adipocytes. American Journal of Physiology-Endocrinology and Metabolism, 2009;296: E1326-E1334.

38. Costa-Urrutia, P., Flores-Buendía, A. M., Ascencio-Montiel, I., Solares-Tlapechco, J., Medina-Campos, O. N., Pedraza-Chaverri, J., ... \& Rodríguez-Arellano, M. E. Antioxidant Enzymes Haplotypes and Polymorphisms Associated with Obesity in Mexican Children. Antioxidants, 2020;9: 684

39. Forcina, G. C., \& Dixon, S. J. GPX4 at the crossroads of lipid homeostasis and ferroptosis. Proteomics, 2019;19: 1800311.

40. Dixon, S. J., Winter, G. E., Musavi, L. S., Lee, E. D., Snijder, B., Rebsamen, M., ... \& Stockwell, B. R. Human haploid cell genetics reveals roles for lipid metabolism genes in nonapoptotic cell death. ACS chemical biology, 2015;10: 1604-09.

41. Kagan, V. E., Mao, G., Qu, F., Angeli, J. P. F., Doll, S., St Croix, C., ... \& Bayır, H. Oxidized arachidonic and adrenic PEs navigate cells to ferroptosis. Nature chemical biology, 2017;13: 8190.
42. Killion, E. A., Reeves, A. R., El Azzouny, M. A., Yan, Q. W., Surujon, D., Griffin, J. D., ... \& Greenberg, A. S. A role for long-chain acyl-CoA synthetase-4 (ACSL4) in diet-induced phospholipid remodeling and obesity-associated adipocyte dysfunction. Molecular metabolism, 2018;9:43-56. 